\title{
A TRADUÇÃO DA/DÁ ORIGEM: NOTAS SOBRE MITO, ROMANCE E ENCONTRO DE MUNDOS
}

\section{ORIGINS OF TRANSLATION, TRANSLATION OF ORIGINS: NOTES ON MYTH, NOVELS AND ENCOUNTER OF WORLDS}

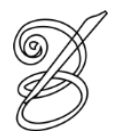

Alexandre NODARI*

Universidade Federal do Paraná

Curitiba, Paraná, Brasil

Resumo: Essas notas, apesar de seu tom muitas vezes excessivamente afirmativo, visam, antes de mais nada, situar um campo problemático, um conjunto de problemas comum ou transversal a práticas discursivas diversas: a prosa de ficção, com destaque para o gênero romance e a ficção científica, o mito, o canto xamânico, etc. Qual a sua relação originária com a tradução? Como podemos repensar esta a partir da imagem do encontro de mundos?

Palavras-chave: Tradução. Mito. Romance. Encontro de mundos.

Abstract: These notes, notwithstanding their overly affirmative tone, seek to establish a problematic field, a set of problems common (or transversal) to distinct discursive practices: prose fiction (with special attention to novels and science fiction), myths, shamanic chants, etc. What is their originary relationship with translation? Can we rethink the task of translation making resort to the image of an encounter of worlds?

Keywords: Translation. Myth. Novel. Encounter of worlds.

RECEBIDO EM: 2 de setembro de 2019

ACEITO EM: 25 de novembro de 2019

PUBLICADO EM: março 2020 
$\S$

- Como se sabe, em sua origem medieval, o romance se vincula à tradução, ainda que por vezes de modo fingido: "o romanz a princípio assinala a tradução por completo tradicional em língua vulgar, mais precisamente em francês ou a tradução fictícia do latim" (Stierle, 2006: 32). A finta tradutória constituía uma estratégia em todo análoga àquela de atribuir a outrem (alguma figura reconhecida do passado ou presente) a autoria do próprio texto, conferindo-lhe, assim, autoridade. Afinal o termo auctor, na Idade Média, mais do que simplesmente designar qualquer um que escrevesse um texto, um livro, um poema, implicava também uma autoridade a ser "respeitada e acreditada"; a obra de um auctor deveria ter "valor intrínseco" e "autenticidade". "Os escritos de um auctor", continua Alastair Minnis (2010: 10), "continham, ou possuíam, auctoritas no sentido abstrato do termo, com suas conotações fortes de veracidade e sagacidade". Remetendo a origem de um texto a outro (seja na atribuição autoral, seja na tradução finta, seja na mescla de dois), cria-se uma distância, temporal e/ou espacial, que fornece a autoridade desejada (pense-se nas duas figuras mestras da narração segundo Benjamin: o moribundo e o viajante). Todavia, nesse gesto de distanciamento, presente já na relação entre o aedo e a Musa, abre-se também a possibilidade de que o texto se dobre sobre si mesmo, que ele se instaure como "co-operação" (Brandão, 2015). Não é um acaso, assim, que o marco do ingresso do romance na modernidade, Dom Quixote, se afirme em seu prefácio, de modo paródico, como uma tradução - uma falsa tradução, ou melhor dizendo, uma tradução sem original. Mas se o romance não traduz um texto - no sentido estrito do termo -, o que exatamente ele traduz? Qual a sua origem rasurada?

\section{"[N]o princípio da literatura está o mito, assim como no fim."} (J.L. Borges)

§. Um topos clássico estabelece a relação entre a distância temporal e a liberdade de fabulação poética. Assim, Sócrates dirá: "não sabendo a verdade sobre os eventos do passado, concedemos tanto verossimilhança quanto possível ao pseudos" (Rep., 382d; trad. modificada). Que ele esteja, nessa passagem, se referindo às "mitologias", se justifica plenamente, pois, de acordo com esse topos, o ponto mais afastado temporalmente é a origem primeira - e é esse afastamento que dá origem ao mito.

§. Segundo Lévi-Strauss, o mito é, por excelência, o discurso sem sujeito: trata da origem, mas não tem ele mesmo uma origem. Todavia, é justamente por ele ser enunciado por ninguém, que pode ser enunciado por qualquer um (cf. Comin, 2019), e, por consequência, (quase) infinita e (quase) integralmente traduzível: "O mito poderia ser definido como modo do discurso em que o valor da fórmula traduttore, traditore tende praticamente a zero" (Lévi-Strauss, 2008: 225). Isso porque o próprio mito é tradução: "contar é sempre recontar, e transformar (...). A bem dizer, nunca existe texto original: todo mito é, por natureza, tradução. Origina-se de outro mito, proveniente de uma população vizinha mas estrangeira, ou de um mito
§. Na modernidade, o espaço virá progressivamente a substituir o tempo na formulação do topos que relaciona distância e fabulação. Assim, Torquato Tasso, em seus Discorsi dell'arte poética, de 1587, primeiro dirá que quanto mais a história recua, dos fatos recentes aos longínquos, mais material fornece para sua ficção, para, mais adiante, especializar a distância que dá asas ao artista: "Por conseguinte, o poeta deve evitar os argumentos fintos, sobretudo se finge haver sucedido alguma coisa em país vizinho e conhecido e entre nações amigas, porque entre povos distantes e nos países desconhecidos podem fingir muitas coisas levemente, sem tirar a autoridade da fábula" (citado em Stierle, 2006: 49). Nas Fábulas de 
anterior da mesma população, ou ainda contemporâneo, mas pertencente a outra subdivisão social - clã, subclã, linhagem, família, confraria - que o ouvinte busca desmarcar traduzindo-o a seu modo, em sua linguagem pessoal ou tribal, ora para dele apropriar-se ora para desmenti-lo, e deformando-o sempre, portanto (...). Encarado de um ponto de vista empírico, todo mito é a um tempo primitivo em relação a si mesmo e derivado em relação a outros mitos; não se situa $\mathrm{em}$ uma língua e $\mathrm{em}$ uma cultura ou subcultura, mas no ponto de articulação destas com outras línguas e outras culturas. De modo que o mito nunca é de sua língua, é perspectiva sobre uma língua outra" (LéviStrauss, 2011: 621-2; grifos no original).

§. Discurso originalmente traduzido e traduzível, não atestável e por isso fonte de toda autenticação, o mito é a origem de toda verdade e de toda mentira, e da tradução da verdade em mentira e da mentira em verdade, ou seja, daquele discurso que é indiferente a essa distinção, que deliberadamente as confunde, que se situa nesse tempo fora do tempo do mito, o tempo originário (cf. Nodari, 2017), sem origem embora fonte de toda origem: a ficção, arte das distâncias e do distanciamento.

§. Na segunda parte d'A origem dos modos à mesa, intitulada "Do mito ao romance", LéviStrauss (2006: 118) parece postular a distância (e inferioridade espiritual) iniludível que separa este em relação àquele: "Mas não é isso, sempre, um romance? O passado, a vida, o sonho, carregam imagens e formas deslocadas que assediam o escritor, quando o acaso, ou alguma outra necessidade, desmentindo aquela que foi outrora capaz de engendrá-los e dispô-los numa verdadeira ordem, preservam ou recuperam nelas os contornos do mito. No entanto, o romancista voga à deriva entre esses corpos flutuantes que o calor da história, provocando um degelo, separa dos blocos de que faziam parte. Ele recolhe esses materiais e os reutiliza como eles se apresentam, não sem
La Fontaine, de 1668, o topos já se encontra cristalizado em uma imagem, a das terrae incognitae a serem exploradas como fonte da fabulação, não, porém, desvinculada da sua origem temporal na antiguidade grega: "Sendo a invenção das artes um direito de primogenitura, / Devemos louvar a Grécia antiga. / Mas não se pode segar esse campo tanto / Que os pósteros aí não encontrem o que recolher. / O fictício é um país cheio de terras desertas: / Todos os dias nossos autores aí fazem descobertas" (citado em Stierle, 2006: 56). Essa imagem terminou por se tornar um lugar comum, persistindo até hoje e colando-se à do romance. Assim, Milan Kundera (2009: 46, 47) irá dizer, incluindo a cartografia em sua definição, que "Os romancistas desenham o mapa da existência descobrindo esta ou aquela possibilidade humana" e que Broch, por exemplo, "descobriu um território desconhecido da existência". Mas de onde se origina a constância da associação do ficcionista com o explorador?

§. Embora a imagem do descobrimento ou da exploração de novos e desconhecidos territórios seja pré-moderna, o crescimento exponencial de seu uso na Modernidade não pode ser dissociado, evidentemente, do descobrimento e da exploração, em sentido literal, de novos e desconhecidos territórios, ou melhor, como o nome já diz, de um novo mundo: outro mundo, mundo outro, que parece colocar em xeque não só a unicidade mas também a temporalidade do velho mundo (lembre-se de como a sua datação a bíblica - foi posta em questão pelas descobertas). A Conquista do Novo Mundo, o encontro e choque entre cosmoi (guerra de mundos), dilatou tempo e espaço - e é nessa dilatação do espaço-tempo que se situa a literatura moderna, ao menos a prosa de ficção, cujo emblema é o romance.

§. Não se pode enfatizar o suficiente essa correlação, justamente por ela ser constantemente ignorada, como, por exemplo, pelo próprio Kundera (2009: 13-4, 
perceber confusamente que pertencem a um outro edifício e que irão se tornar cada vez mais raros na medida em que ele é carregado por uma corrente diferente daquela que os mantinha reunidos (...). [O] herói do romance é o próprio romance. Ele conta sua própria história: não apenas que ele nasceu da extenuação do mito, mas que se reduz a uma busca extenuante pela estrutura, aquém de um devir que espia de perto, sem poder encontrar, dentro ou fora, o segredo de um antigo frescor, a não ser talvez em alguns refúgios em que a criação mítica ainda permanece vigorosa, mas nesse caso, e contrariamente ao romance, à sua revelia". A descontinuidade entre mito e romance se produziria, segundo ele, por meio da proliferação do contínuo sobre o que antes era discreto: a "degradação irreversível a partir da estrutura em direção à repetição" (ibid.:118), “degradação [que] começa quando estruturas de oposição dão lugar a estruturas de reduplicação -

86 episódios sucessivos, mas todos no mesmo molde. E se encerra no momento em que a própria reduplicação assume o lugar de estrutura. Forma de uma forma, ela colhe o derradeiro murmúrio da estrutura expirante. Já sem nada, ou quase nada, a dizer, o mito só dura sob a condição de repetir-se" (ibid.:1167). Lévi-Strauss chega a essa definição através da análise de certos mitos ameríndios que parecem operar a passagem do mito ao romance, formas liminares em que, para parafraseá-lo, o mito extenua a si mesmo: (quase-)mitos (ou quase-romances) em que, por exemplo, "os encontros absurdos com animais extravagantes [raramente] se traduzem (...) por uma contribuição positiva à ordem natural"; animais e seres imaginários que "surgem de improviso no relato, desligados dos paradigmas míticos a que pertencem, fora dos quais é impossível interpretá-los" (ibid.:115). Eduardo Viveiros de Castro (2015 : 196; grifo no original) sugeriu pensar tais variações não como produtos de uma "involução histórica linear do mito em romance", e sim como "um devir lateral interno ao mito, que o faz entrar em um regime da multiplicidade, estilhaçando-o
15): "Descobrir o que somente um romance pode descobrir é a única razão de ser de um romance. O romance que não descobre algo até então desconhecido da existência é imoral (...). Acrescento ainda isto: o romance é a obra da Europa; suas descobertas, embora feitas em línguas diferentes, pertencem a toda a Europa. A sucessão das descobertas (não a soma do que foi escrito) faz a história do romance europeu (...). Quando Deus deixava lentamente o lugar de onde tinha dirigido o universo e sua ordem de valores, separara o bem do mal e dera um sentido a cada coisa, Dom Quixote saiu de casa, e não teve mais condições de reconhecer o mundo. Este, na ausência de um Juiz supremo, surgiu subitamente numa temível ambiguidade; a única Verdade divina se decompôs em centenas de verdades relativas que os homens dividiram entre si. Assim, o mundo dos tempos modernos nasceu e, com ele, o romance, sua imagem e modelo (...). Dom Quixote partiu para um mundo que se abria amplamente diante dele. Ali podia entrar livremente e voltar para casa quando quisesse. Os primeiros romances europeus são viagens através do mundo, que parece ilimitado". É verdade que o mundo europeu se tornou ambivalente e o Deus que garantia a ordem e a unicidade saiu de cena - mas isso porque (e para além de toda a história do pensamento e da sociedade europeias) outros mundos entraram em choque com ele. O romance e as suas descobertas podem até ser obra da Europa e pertencerem a ela. Mas a sua origem está na América de 1492, enquanto ponto de contato, dobra espaçotemporal em que colidem mundos. A partir de então, não há só um mundo em vigor, não há só um mundo possível - não só o Um é que é possível.

§. Todavia, a América de 1492 não marca apenas o início de uma colisão inaudita de mundos, mas também o começo do fím do Mundo, o Antropoceno (conforme sugerido por Lewis e Maslin (2015)), pela tentativa de unificação da multiplicidade em um só 
em fragmentos de uma rapsódia tão infinita quanto esparsa sobre os quaseacontecimentos". De maneira semelhante, ao invés de se só considerar estruturalmente o limite descontínuo que separa o mito do romance, poder-se-ia também investigar, por meio de uma pragmática, os diversos agenciamentos dos limiares entre o mítico e o prosaico, que tendem tanto para a prosificação do mito quanto para a mitificação do prosaico, e contaminam reciprocamente um campo pelo outro. Pensese, por exemplo, nas estratégias atuais de povos indígenas de publicação de suas narrativas, que inserem o mítico (descontínuo) no prosaico (contínuo), forçando, nesse gesto, os limites e a definição do campo literário, do que entendemos por literatura, ou então, no xamanismo, que muitas vezes consiste na inserção do prosaico em operações e planos míticos, como entre os Marubo, para os quais a cura xamânica de uma patologia envolve descobrir e cantar a sua origem mitológica (cf. Cesarino, 2011 e 2015). Em ambos os casos, o que temos é uma tradução: do mito em prosa, e da prosa do mundo na linguagem mítica, do tempo da origem em tempo de agora e vice-versa, do mundo originário ao mundo atual e viceversa. E, ao fim e ao cabo, todo relato de um mito não consistiria numa atividade que visa não só afirmar a descontinuidade entre esse outro mundo e esse nosso mundo, mas também sobrepô-los, ler um a partir de outro, torná-los legíveis, traduzi-los? Isso, ao menos, me parece ser o que se pode extrair da citação indireta que Orlando Calheiros (2014: 14), em sua etnografia sobre os Aikewara, faz de uma conversa que teve com Muretama: "[Ela] Dizia-me que, da mesma maneira que ela traduzia as palavras de seu marido para o meu idioma, a se'eng-kwera [literalmente: fala-deoutrora, mito] traduzia tudo aquilo que existia nesse mundo; ele não apenas descrevia a sua origem, mas indicava também o seu sentido".

§. Em "Pontos de vista sobre a floresta amazônica: xamanismo e tradução", Manuela Carneiro da Cunha (1998: 8) sintetizou a projeto de extermínio e suicídio em massa pelo Homo (cf. Ludueña, 2012). Ou seja, trata-se do encontro não só de cosmoi, mas de cosmologias, de modos diferentes de lidar com o choque de mundos, o cruzamento entre tensões ou forças metacósmicas distintas. De um lado, como vimos, o estranhamento de si e a abertura para a transformação. De outro, a "estandardização do homo sapiens" (Galvão e Ferraz, 2013), a uniformização ambiental do mundo como casa do homem moderno ("cosmopolita" ou "universal", esse habitante de shopping centers e hotéis padronizados mundo afora), indissociável da destruição de formas humanas e nãohumanas de vida, e, portanto, do empobrecimento paulatino e destruição repentina do próprio mundo unificado: "A unidade da humanidade significa: ninguém pode escapar em nenhum lugar" (Kundera, 2009: 18). Ou, para usar a imagem dos dois fundadores dos tempos modernos de Kundera: de um lado, Quixote, tendo como "única certeza a sabedoria da incerteza" (ibid:: 14; grifo no original), de outro, Descartes, a passagem sem solução de continuidade da dúvida (ambiguidade do mundo) à certeza. (E no meio, como terceiro incluído, incorporação agônica da dualidade, da dúvida, o Descartes transportado aos trópicos por Leminski em Catatau). O romance moderno não só nasce desse conflito, como também é ele mesmo esse conflito entre mundos e cosmologias: mobiliza diferentes estratégias, através da linguagem, de relação entre o familiar e o desconhecido, o próprio e o alheio, o eu e o outro. Espaço do unheimlich, doinfamiliar. Espaço da tradução de mundos?

§. Se "Dom Quixote partiu para um mundo que se abria amplamente diante dele", como diz Kundera, é preciso lembrar que ele não viaja desacompanhado. Ao seu lado está Sancho Pança, um subalterno, mas também, e por isso mesmo, um tradutor de mundos, alguém que está entre o mundo encantado da cavalaria e o mundo prosaico, e que precisa constantemente mediá-los. Em certo 
relação entre a operação xamânica de visitar outros mundos (entre os quais muitas vezes o mítico) e o crescimento exponencial em situações de fim de mundo derivados de guerras de mundos, a unificação de mundos em um só mundo - a colonização: "Observou-se muitas vezes o extraordinário florescimento do xamanismo em situações de dominação de tipo colonial, ou mais exatamente quando povos são capturados nas engrenagens do sistema mundial (...). Observou-se, também, que esse florescimento não atingiu apenas os povos submetidos: a clientela dos xamãs é, na maior parte dos casos, regional, quando não ainda mais ampla, sem distinção de origem étnica, e isso desde o início da colonização. Desde o fim do século XVI, no Brasil, a Inquisição perseguia os colonos - alguns, aliás, personagens importantes - que seguiam os profetas indígenas das chamadas 'santidades'. Em nossos dias, um outro exemplo estaria nos

88 grupos urbanos de tipo New Age. O crescimento do xamanismo pode se manifestar, assim, no interior de certos grupos indígenas, em movimentos milenaristas, mas também no meio urbano, na maioria das vezes (...) com técnicas heteróclitas que se autoproclamam tradicionais". O crescimento da atividade xamânica, de trânsito e mediação entre planos (mundos) cosmológicos, na fronteira (no duplo sentido de limite/limiar e de entrada do empreendimento colonizador) entre mundos indígenas e mundo branco, constitui mais uma evidência a favor da associação, hoje comum, feita entre a comunicação xamânica de pajés de povos ameríndios com seres de outros planos, e a transmissão de discursos destes a outros integrantes da aldeia, e a tradução. Todavia, deve-se ter em mente que, ao contrário dos turgimões, línguas ou intérpretes (e note-se que muitas vezes os xamãs também ocupam essas posições), a tradução xamânica não necessariamente é de ordem linguística. Embora entre alguns povos se trate também dela, muitas vezes com o auxílio de artefatos mágico-técnicos tão avançados e eficazes quanto o tradutor universal de Star Trek, sentido, Sancho epitomiza a função da magia ou a figura do feiticeiro no romance, invocados, seja por Quixote seja pelo Cura e Barbeiro, para justificar as súbitas transformações - de dragões em moinhos de vento, por exemplo -, i.e., para manter o mundo equívoco. A tradução como equivocação (magia) é o que não permite estabelecer que mundo está em vigor, ou melhor, é o que impede um só mundo de vigorar.

§. A dualidade que parece estar inscrita no romance moderno sintomaticamente se manifesta em sua origem dual: Dom Quixote, mas também Robinson Crusoe "verdadeiro símbolo da conquista britânica", "autêntico protótipo do colonizador" (citado em Derrida, 2011: 38), nas palavras de James Joyce, e que esteve, junto com a revolução negra haitiana, na base da dialética do senhor e do escravo de Hegel (cf. Buck-Morss, 2017). Segundo uma visão corrente, embora acrítica, a ligação do romance moderno com o individualismo burguês encontraria aqui sua origem na forma de uma hipóstase, a figura do selfmade man isolado na ilha deserta e que cria para si um mundo, além de escrever um livro a respeito. Todavia, como apontou Deleuze (2006: 312), "a imagem da origem pressupõe o que ela pretende engendrar": "tudo o que Robinson tirou dos restos do naufrágio", uma série de equipamentos e mantimentos com os quais ele, ao invés de criar um mundo, coloniza outro: "o mundo reproduzido a partir desta origem é o equivalente do mundo real, isto é, econômico". Além do que, a ilha não é nada deserta..., pois o êxito de Robinson depende de um outro, que ele captura (se apossa) e nomeia - fazendo dele seu língua, seu tradutor: Sexta-feira. A fixação ideológica pela relação entre $\mathrm{o}$ romance $\mathrm{e} o$ individualismo modernos perde de vista que no centro da cena está a margem, que o indivíduo desbravador vem sempre acompanhado (e depende) de um subalterno - o romance é sempre dual. Mas aqui, no 
como os "inaladores-mediadores rewe" marubo (cf. Cesarino, 2011), entre tantos outros, a tradução que está em jogo é de outra ordem, pois a língua (dos outros planos) é a mesma (que a do xamã e de sua aldeia). Tomemos o caso dos cantos Kĩsêdjê, exemplar na medida que o que temos neles não é uma poética da tradução, e sim a traduçãocomo poética (Gontijo, 2018): "Apesar", diz Seeger (2015: 135), “de os Kĩsêdjê aprenderem a música no reino da natureza, o que cantam (e portanto o que canta o reino da natureza) não mantém uma relação sônica com os sons de animais, plantas, pássaros, peixes ou insetos que seja passível de gravação em fita. Os cantos dos animais - o que as pessoas ouvem nas aldeias dos animais - são inteiramente diferentes de seus apelos nas florestas, que se chamam $k a$, e se poderia traduzir por 'grito' ou 'latido'. 'Virar pássaro', no sentido de a pessoa perder seu espírito e ir morar com os pássaros, e tornar-se capaz de ver e ouvir a realidade essencial da vida social dos pássaros - que, em muitos aspectos, é a mesma que os humanos vivem hoje, e radicalmente diversa do habitat natural e dos sons aparentes dos animais". Assim, por exemplo, "para os Kĩsêdjê, em vez do som aparente de pássaros individuais, são os cantos que dizem cantar as espécies naturais quando estão em grupo cantos que os especialistas, os únicos que podem ouvi-los, ensinam a aldeia". Mas se não é a língua, o que então se traduz? Uma resposta sucinta seria: todo o resto. Afinal, se nesse tipo de tradução o "texto" permanece idêntico, se repete, o que muda, o que difere, então, é o mundo.A "tarefa do tradutor" não seria assim a de traduziro texto, mas o mundo de/em que este fala. relato de Defoe, falsificação extrema da figura do nativo, não há tradução, só transmissão. Não há traição, só tradição. Aqui, a magia cede à técnica, a equivocação à equivalência. E o Novo Mundo se torna apenas uma nova versão do velho.

§. O que as hipóteses de Kafka (2002) sobre Dom Quixote e de Coetzee (2016) sobre Robinson Crusoe - as de que os verdadeiros autores dos romances fundadores da variante moderna talvez sejam Sancho Pança e SextaFeira - postulam é, por um lado, que a tradução constitui uma fala originária, uma fala que origina o romance, e, por outro, que a possibilidade do subalterno falar está ligada a sua necessidade de traduzir. O subalterno pode falar na medida em que traduz, na medida em que trai a transmissão hereditária e unívoca da Fala. Fala de segunda mão, fala elevada a segunda potência. O paradoxo de Menard (Borges, 2009: 846; tradução nossa) - o de que, apesar da identidade textual absoluta entre o relato original e o derivado, este "é mais sutil que o de Cervantes" e "quase infinitamente mais rico" - se elucida aqui. Se Sexta-Feira é o autor de Robinson Crusoe (ou seja, se ele o escreveu mas atribuiu a sua autoria a Robinson), então tudo muda: da perspectiva do colonizador, passamos à perspectiva do subalterno sobre o colonizador, o que torna o romance um pastiche (assim como Defoe pastichava o ensaio de Montaigne na passagem da fuga do nativo do ritual canibal) até mesmo de si mesmo, e o relato fundador do individualismo moderno se revela um engodo. Uma história mal contada - de um mau-encontro de mundos.

\section{alienações}

A passagem da voga, que se inicia no fim do século XIX e termina em meados do XX, do romance de aventura (derivado dos relatos de viagem aos novos mundos, e que estão entre a fábula - voluntária ou não - e o documento, precursores tanto da antropologia quanto do 
romance modernos) ao de ficção científica, do outro terreno ao extraterrestre, do fora deste mundo ao fora em outro mundo, parece atestar suficientemente como a história do gênero historia também o conflito cosmológico e sua triste resolução: não há mais fora aqui, portanto temos de buscar lá fora o Fora. "Uma vez caducado o exotismo da geografia terrestre como figuração da ânsia da aventura, o romancista se volta para a geografia sideral em planetas que sua fantasia não tem maiores dificuldades em inventar concebe outros e mais descabelados exotismos", afirma, nesse sentido, José Paulo Paes (1990: 23). Da antropologia, passaríamos à xenologia (cf. Valentim, 2018). Além disso, numa volta-redonda, a distância espacial se veria substituída pela temporal como originária da fabulação, embora agora com o vetor invertido: o futuro, e não o passado. Entretanto, não é só isso. Pois o outro fora que se encontra lá fora é também um outro do dentro: se a globalização (a vitória da cosmologia unificante do Homo) implicou que a presença de outros mundos aqui se desliteralizasse, se tornasse uma metáfora, o que a ficção científica faz é (re)literalizar (em outro lugar) o que foi metaforizado, o que adiciona um elemento de horror o de que não conseguimos ver (mais) a multiplicidade de mundos nesse mundo. Verdade que vale retrospectivamente, num efeito de dobra temporal, pois revela que também romances de aventura não se confrontaram de fato com a alteridade, a não ser na forma da negação do próprio (o que, aliás, pode ser dito igualmente de ficções científicas). O futuro que está em jogo não deixa de ser uma alteridade passada, que se deixou passar e por isso não cessa de passar, de maneira que se sobrepõem diferentes distâncias: "as ferramentas são do futuro", diz P.K. Dick sobre um de seus romances, "o cenário está no futuro, mas as situações são realmente do passado" (citado em: Foster, 2005: 170-171). Do mesmo modo, a passagem da literatura utópica à distópica (uma e outra, embora a segunda mais que a primeira, relacionadas à ficção científica) não é apenas uma ruptura ligada à história política do século $\mathrm{XX}$-, mas também uma continuidade, um efeito de retroação: as distopias também revelam o que havia de mais distópico nas utopias.

É sintomático que o horror supremo emerja justo nesse período de transição, na figura de um Fora (quase-)absoluto, exterior ao próprio tempo e espaço e que se oculta sob os lugares mais comuns, as zonas mais provincianas: Lovecraft (cf. Ludueña, 2013). Paralelamente, pois, à ascensão da ficção científica e das distopias, a prosa de ficção verá surgir sem cessar e até hoje estratégias as mais variadas, cujo epítome é o horror, de dar a ver o estranho (recalcado, oculto sob o hábito, seja como for) no mais familiar, da ostranenie formalista aos enredos de Clarice Lispector.

§. O monolinguismo - o advento, como gesto do projeto unificador, das línguas nacionais pelos Estados modernos (processo no qual toma parte a formação das chamadas literaturas nacionais) - é a forma-Estado da língua, que acarreta a forma-Estado da tradução. Nele, o 
traduzir deixa de ser imanente ao falar, exercício ao mesmo tempo intra- e extra-língue, necessário em ambientes que não conhecem uma (só) língua, que não conhecem $a$ língua, para passar a ser uma atividade interlíngue, entre línguas estáveis, entre monolinguismos, entre Estados. O tradutor se torna juramentado, e sua prática, cosmopolita. Mas o monolinguismo não existe (como não existe o Maior, segundo Deleuze e Guattari), e a traição do subalterno tradutor cosmopolítico não cessa de produzir e revelar o multilinguismo inerente a todo falar. Não há fala senão derivada, não há língua senão outra, não há dizer que não seja traduzir.

§. Poder-se-ia repensar o modelo da tradução interlinear proposta por Walter Benjamin (2008), a contaminação de uma língua pela sintaxe (leis) da outra de modo a obter uma "língua pura", visando não uma unidade linguística, e sim a multiplicidade originária. De modo semelhante, pensando a tradução de forma ampla, que diz respeito às "relações transculturais", Wolfgang Iser (2018: s.p.) irá dizer que ela "deve negociar o espaço entre estranhamento e familiaridade". Por um lado, "demanda a transposição de uma cultura estrangeira em uma cultura própria". Por outro, "para que uma cultura estrangeira se torne compreensível, é inevitável uma mudança de atitude em relação à cultura familiar, invadida por algo diferente". Tratar-se-ia da "tradução intercultural mútua por meio de um looping recursivo". Não haveria familiarização do estranho sem estranhamento do familiar. Não haveria tradução sem contaminação.

§. Contudo, não é só de línguas e de culturas que falamos, mas de mundos. Que a questão cosmológica não cesse de se colocar, mesmo que sob diferentes declinações, se deixa ver no debate sobre mundos ficcionais, a relação entre prosa de ficção e mundos possíveis (cf. Doležel, 2000; Ronen, 1994; Pavel, 1986). Se a maioria dos autores envolvidos na discussão confere aos mundos apresentados nos romances uma autonomia ou soberania em relação ao nosso - crendo, assim, resolver pela tangente o problema da mimese -, o estatuto problemático de tal autonomia ou soberania se manifesta quando do problema da identidade transmundo (a presença ou variação de personagens, cenários, etc. históricos e atuais em diversos mundos). E a autonomia ou soberania naufragam diante de uma evidência óbvia (com o perdão da tautologia): "não menos problemática", diz Stierle (2006: 88), "é a pesquisa, com que o discurso ficcional ganharia uma nova dignidade, segundo a qual cada discurso ficcional é subordinado a 'outro mundo' coerente em si. Pois a própria linguagem é o horizonte insuprimível de 'nosso mundo', que põe em perspectiva todos os outros e possíveis mundos". Mas será que a recíproca não é verdadeira, ou seja, que, através dela, os outros mundos também perspectivam o nosso? Pensemos na contaminação e modificação de nosso mundo pela prosa de ficção, sintomatizado em termos como "quixotesco", "bovarismo", "kafkiano". A linguagem atesta que, em todo romance, há mais de um mundo, que dois mundos se sobrepõem - para se equivaler ou para se equivocar. É o ponto de contato entre mundos. A sua tradução - contaminação - recíproca.

§. Em Os próprios deuses, Isaac Asimov (2010) apresenta um cenário em que a troca (contaminação) de elementos químicos entre dois universos acarreta algo mais: a contaminação recíproca de suas leis cósmicas, de suas cosmologias. Todavia, no romance, a troca, a tradução, parece estar regidas pela suposição de que os princípios da termodinâmica teriam uma validade meta-universal, meta-cósmica, ou seja, de que ela cessaria quando as leis cósmicas de ambos os universos se tornassem iguais. Assim, a contaminação recíproca tenderia à equivalência. Mas não há nada que torne necessário esse meta-princípio: antes, ele parece ser mais uma versão do "preconceito a favor do atual", de que falava Meinong, ao postular o equilíbrio termodinâmico do "nosso" mundo como sendo válido também para a 
relação entre ele e outros mundos. E se não houver um meta-princípio, ou melhor, se este for a sobreposição cambiável de princípios cosmológicos divergentes e, portanto, efeito da contaminação e não seu regulador $a$ priori? Uma equivocação e não uma equivalência? Entendida desse modo, a contaminação tenderia ao infinito, ao múltiplo e não à unidade, à transformação e não à estabilidade. Daí a cosmopolítica envolvida em toda tradução de mundos. Daí a tarefa cósmica de todo tradutor.

§. No começo de Matrix Revolutions, o protagonista Neo acorda em uma estação de trem que leva do mundo virtual ao real e vice-versa. Mas onde se situa esse "expresso transumwéltico" (cf. Catren, 2017 e 2016)? Se a ilusão dos ingênuos está em querer colocá-lo em um ou outro mundo, a dos cosmopolitas está em postular para ele um meta-mundo. Pois o terceiro mundo desse trem transmundo não é um outro mundo, mas aquilo que sobrepõe dois mundos, que faz todo mundo outro. Lugar da tradução. Lugar da ficção. Lugar do mito. Origem dos mundos.

\section{REFERÊNCIAS}

Asimov, Isaac. (2010). Os próprios deuses. Trad. Silvia Mourão. São Paulo: Aleph.

Benjamin, Walter. (2008). A tarefa do tradutor, de Walter Benjamin: quatro traduções para o português. Org. Lucia Castello Branco. Belo Horizonte: FALE/UFMG.

92 Borges, Jorge Luis. (2009). "Pierre Menard, autor del Quijote". In Obras completas, I: 19231949. Edição crítica. Comentários de Rolando Costa Picazo e Irma Zangara. Buenos Aires: Emecé, p. 842-847.

Brandão, Jacyntho Lins. (2015). Antiga musa (arqueologia da ficção). 2. ed. rev. ampl. Belo Horizonte: Relicário.

Buck-Morss, Susan. (2017). Hegel e o Haiti. Trad. Sebastião Nascimento. São Paulo: n-1 edições.

Calheiros, Orlando. (2014). Aikewara: esboços de uma sociocosmologia tupi-guarani. Tese de doutorado defendida no Museu Nacional/UFRJ.

Carneiro da Cunha, Manuela. (1998). Pontos de vista sobre a floresta amazônica: xamanismo e tradução. Mana, 4(1): 7-22.

Catren, Gabriel. (2017). Pleromática o las mareaciones de Elsinor. Buenos Aires: Hekht Libros.

Catren, Gabriel. (2016). The "Trans-Umweltic Express". Disponível em http://www.glassbead.org/article/the-trans-umweltic-express/?lang=enview

Cesarino, Pedro de Niemeyer. (2011). Oniska: poética do xamanismo na Amazônia. São Paulo: Perspectiva.

Cesarino, Pedro de Niemeyer. (2015). Montagem e formação do mundo nas artes verbais marubo. species - revista de antropologia especulativa, 1: 66-78. 
Coetzee, J.M. (2016). Foe. Trad. José Rubens Siqueira. São Paulo: Companhia das Letras.

Comin, Clarissa. (2019). O grau zero da ficção: desmolduramento enunciativo em Delírio de Damasco. Estudos de Literatura Brasileira Contemporânea, 57.

Deleuze, Gilles. (2006). Lógica do sentido. Trad. Luiz Roberto Salinas Fortes. São Paulo: Perspectiva.

Derrida, Jacques. (2011). La bestia y el soberano, v. 2 (2002-2003). Trad. (para o castelhano) Luis Ferrero, Cristina de Peretti e Delmiro Rocha. Buenos Aires: Manantial.

Doležel, Lubomír. (2000). Heterocosmica: Fiction and Possible Worlds. Baltimore: The John Hopkins Press.

Foster, Hal. (2005). O retorno do real (cap. 5). Concinnitas, 8 (1): 162-186.

Galvão, Patrícia (Pagu); Ferraz, Geraldo. (2013). A famosa revista. São Paulo: Descaminhos.

Gontijo Flores, Guilherme. (2018). "Perder o espírito: a tradução como poética nas performances dos Kĩsêdjê”. In Ribeiro, Gustavo S.; Pinheiro, Tiago G.; Veras, Eduardo H. N. (orgs.). Poesia contemporânea: reconfigurações do sensível. Belo Horizonte: Quixote, pp. 147-159.

Iser, Wolfgang. (2018). "Sobre a tradutibilidade". Trad. Clarissa Comin. Disponível em https://subspeciealteritatis.wordpress.com/2018/10/02/primeiro-post-do-blog/

Kafka, Franz. (2002). Narrativas do espólio. Trad. Modesto Carone. São Paulo: Companhia das Letras, p.103.

Kundera, Milan. (2009). A arte do romance. Trad. Teresa Bulhões C. da Fonseca. São Paulo: Companhia das Letras.

Lévi-Strauss, Claude. (2008). Antropologia estrutural. Trad. Beatriz Perrone-Moisés. São Paulo, Cosac Naify.

Lévi-Strauss, Claude. (2011). O homem nu (Mitológicas, v. 4). Trad. Beatriz Perrone-Moisés. São Paulo, Cosac Naify.

Lévi-Strauss, Claude. (2006). A origem dos modos à mesa (Mitológicas, v.3).Trad. Beatriz Perrone-Moisés. São Paulo: Cosac Naify.

Lewis, Simon L.; Maslin, Mark A. (2015). Defining the Anthropocene. Nature, 519.

Ludueña Romandini, Fabián. (2012). A comunidade dos espectros. I. Antropotecnia. Trad. Alexandre Nodari e Leonardo D’Ávila. Desterro: Cultura e Barbárie.

Ludueña Romandini, Fabián. (2013). H.P. Lovecraft: a disjunção no Ser. Trad. Alexandre Nodari. Desterro: Cultura e Barbárie. 
Minnis, Alastair. (2010). Medieval Theory of Authorship. Scholastic Literary Attitudes in the Later Middle Ages. 2. ed. Philadelphia: University of Pennsylvania Press.

Nodari, Alexandre. (2017). Quase-evento: sobre a estoricidade da experiência literária. ELyra: Revista Da Rede Internacional Lyracompoetics, 10: 55-77.

Paes, José Paulo. (1990). A aventura literária: ensaios sobre ficção e ficções. São Paulo: Companhia das Letras.

Pavel, Thomas G. (1986). Fictional worlds. Cambridge: Harvard University Press.

Platão. (2016). A república de Platão. Org. e trad. J. Guinsburg. São Paulo: Perspectiva. Ronen, Ruth. (1994). Possible Worlds in Literary Theory. Cambridge University Press.

Seeger, Anthony. (2015). Por que cantam os Kĩsêdjê: uma antropologia musical de um povo amazônico. Trad. Guilherme Werlang. São Paulo: Cosac Naify.

Stierle, Karlheinz. (2006). A ficção. Trad. Luiz Costa Lima. Rio de Janeiro: Caetés.

Valentim, Marco Antonio. (2018). Antropologia \& xenologia. ECO-Pós, 21(2): 343-363.

Viveiros de Castro, Eduardo. (2015). Metafísicas canibais: elementos para uma antropologia 94 pós-estrutural. São Paulo: Cosac Naify.

\footnotetext{
* Alexandre André NODARI - Graduado em Direito (2006) pela Universidade Federal de Santa Catarina. Mestre (2007) e Doutor (2012) em Literatura pela mesma instituição. Realizou pesquisa pós-doutoral (2012-2013) na Universidade Federal de Santa Catarina. Professor adjunto da Universidade Federal do Paraná, Setor de Ciências Humanas, Departamento de Linguística, Letras Clássicas e Vernáculas. Curitiba, Paraná, Brasil. Curitiba, Paraná, Brasil.

Currículo acadêmico: http://lattes.cnpq.br/3298943752969192

ORCID: https://orcid.org/0000-0001-9519-145X

E-mail: alexandre.nodari@gmail.com
} 